\title{
Foregut duplication of the stomach diagnosed by endoscopic ultrasound guided fine-needle aspiration cytology: case report and literature review
}

Vincenzo Napolitano', Angelo M Pezzullo', Pio Zeppa², Pietro Schettino ${ }^{1}$, Maria D'Armiento², Antonietta Palazzo', Cristina Della Pietra', Salvatore Napolitano ${ }^{1}$ and Giovanni Conzo ${ }^{1 *}$

\begin{abstract}
Gastric duplication cyst (GDC) with a pseudostratified columnar ciliated epithelium is an uncommon malformation supposed to originate from a respiratory diverticulum arising from the ventral foregut. Morphologic appearance of GDCs is variable, depending on the density of their contents. GDCs are often misdiagnosed as solid masses by imaging techniques, and as a consequence they may be wrongly overtreated. We report our case of a 56-year-old man with a $5 \mathrm{~cm}$ hypoechoic mass of the gastroesophageal junction, incidentally detected by transabdominal ultrasonography. Neither transabdominal ultrasonography nor magnetic resonance clearly outlined the features of the lesion. The patient underwent endoscopic ultrasound (EUS), which showed a hypoechoic mass arising from the fourth layer of the anterior gastric wall, just below the gastroesophageal junction. According to EUS features, a diagnosis of gastrointestinal stromal tumor was suggested. EUS-guided fine-needle aspiration cytology revealed a diagnosis of GDC with pseudostratified columnar ciliated epithelium. We therefore performed an endoscopicallyassisted laparoscopic excision of the cyst.

In conclusion, whenever a subepithelial gastric mass is found in the upper part of the gastric wall, a duplication cyst, although rare, should be considered. In this case, EUS-guided fine-needle aspiration cytology could provide a cytological diagnosis useful to arrange in advance the more adequate surgical treatment.
\end{abstract}

Keywords: Gastric duplication cyst, Foregut duplication cysts, Pseudostratified columnar ciliated epithelium, Laparoscopic surgery, Endoscopic ultrasound-guided fine-needle aspiration cytology

\section{Background}

Duplications of the alimentary tract are relatively rare congenital anomalies. Those located in the stomach are very uncommon, constituting between 4 and $9 \%$ of all intestinal duplications [1]. The structure of a gastric duplication cyst (GDC) consists of a smooth muscle coat lined by a mucous membrane, in most cases containing a typical gastric epithelium [2], although a small intestinal or colonic mucosa may also be present. Generally, they are single and do not communicate with gastric lumen. Exceptionally, in GDCs a pseudostratified

\footnotetext{
*Correspondence: giovanni.conzo@unina2.it

1 Department of General and Specialistic Surgery, School of Medicine, Second University of Naples, 5 S. Pansini Street, Naples 80100, Italy

Full list of author information is available at the end of the article
}

columnar ciliated epithelium, more commonly present in the esophageal duplication cysts, can be found. According to Cunningham and colleagues [3], GDCs lined by pseudostratified columnar ciliated epithelium could be better defined as foregut duplication cysts (FDCs) of the stomach.

Diagnosis of a gastric duplication may be difficult even using the most advanced imaging techniques, including endoscopic ultrasound (EUS) [4-6]. Here we report a case of GDC with respiratory epithelium, misdiagnosed as a gastrointestinal stromal tumor (GIST) at EUS. The EUS-guided fine-needle aspiration subsequently performed led to a definite preoperative diagnosis, allowing a proper conservative endoscopically-assisted laparoscopic resection of the cyst.

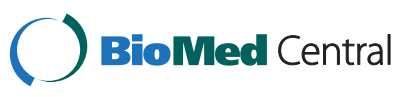




\section{Case presentation}

A 56-year-old man, with a history of B-related chronic hepatitis under antiretroviral treatment, was referred to our surgical department by the Infectious Diseases Unit, where he was under follow-up. The patient did not complain of any symptom concerning the gastrointestinal tract. During an abdominal ultrasonography, a hypoechoic round-shaped mass $4.7 \mathrm{~cm}$ in size, with regular margins, located between the left lobe of the liver and the anterior surface of the pancreatic body, was found. Magnetic resonance imaging confirmed the presence of a cystic mass with complex content, located anteriorly to the gastroesophageal junction.

The patient was then submitted to EUS, in order to better define the structure of the lesion and its relationship with the adjacent organs. EUS showed a hypoechoic mass with slightly heterogeneous internal echoes and regular margins, located just below the gastroesophageal junction (Figure 1). The lesion measured about $4.5 \mathrm{~cm}$ and seemed to be contiguous to the fourth layer of the gastric wall (muscolaris propria). On the basis of the morphologic evaluation, a diagnosis of GIST was suggested. As is usual in a case of suspected GIST involving the upper part of the gastric wall, we tried to obtain diagnostic confirmation through EUS-guided fine-needle aspiration cytology (FNAC). The puncture was practiced using a $22 \mathrm{G}$ needle, which, unexpectedly, penetrated very easily into the mass as it was cystic. We were able to aspirate only a few milliliters of a clear mucus-like fluid, and then a cytological sampling was made from the cystic wall. The collected material was judged adequate by an onsite cytopathologist. The cytological smear showed cylindrical cells isolated or

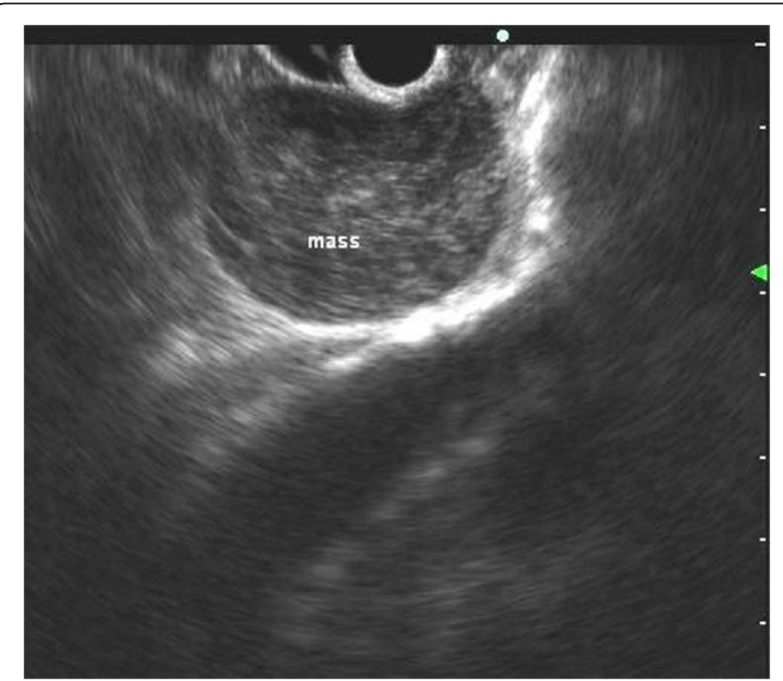

Figure 1 Endoscopic ultrasound features. A hypoechoic mass with a slight heterogeneous texture developing within the gastric wall. aggregated in small groups with a palisade organization (Figure 2). These cells showed long cilia and brush borders similar to the ciliated cells of the respiratory tract. These basal cells had oval nuclei with finely dispersed chromatin and small nucleoli, if any. The background consisted of proteinaceous material containing debris, crystal formations and engulfed hystiocytes. On the basis of these features, a diagnosis of duplication cyst with respiratory epithelium was made.

Later on, the patient underwent a surgical intervention carried out by an open laparoscopic approach with a transhumbelical Hasson trocar (without a Verres needle to obtain the pneumoperitoneum) and four additional trocars (two of $10 \mathrm{~mm}$ and two of $5 \mathrm{~mm}$ ). Once the lesion was clearly identified, the overlying serosa was cut by a harmonic scalpel (Harmonic Ace; Ethicon EndoSurgery, Cincinnati, OH, USA). Through a cautious dissection performed under endoscopic control in order to keep the cyst intact, to prevent perforation of the gastric wall, the mass was totally exposed and then completely resected using a linear endoscopic stapler $\left(\right.$ Echelon $^{\mathrm{TM}}$ 60; Ethicon Endo-Surgery). The surgical procedure was completed by performing a Dor fundoplication. The patient had an uneventful postoperative recovery and was discharged on the seventh postoperative day.

Pathologic examination of the surgical specimen revealed macroscopically a cystic lesion $5 \mathrm{~cm} \times 3 \mathrm{~cm} \times$ $3 \mathrm{~cm}$ in size with a mucoid content. Microscopically the cystic wall consisted of mucosa, subepithelial connective tissue, a layer of smooth muscle and an outer fibrous capsule. Focally the mucosa was lined by gastric foveolar

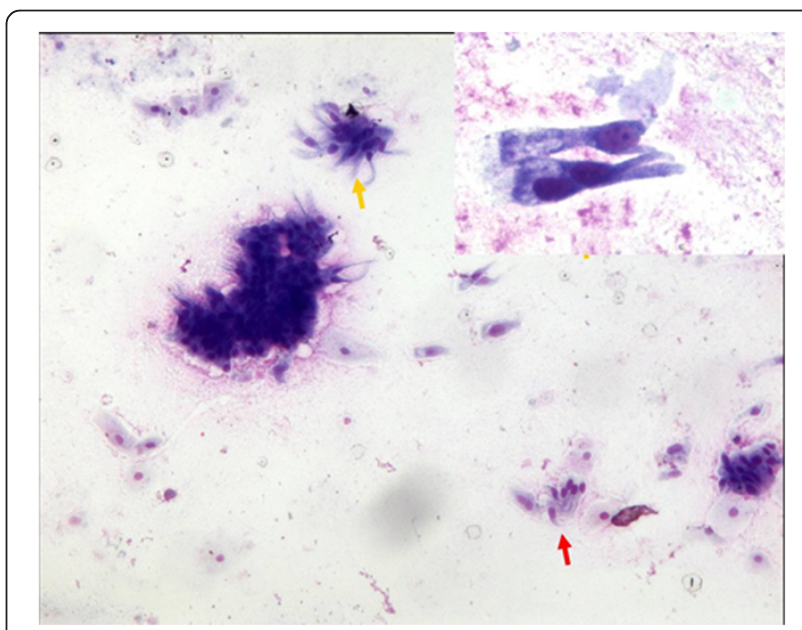

Figure $\mathbf{2}$ Cytology on fine-needle aspiration sampling. Isolated and aggregated cylindrical ciliated cells (yellow arrows) in a background containing debris and squamous cells. Note characteristic palisade arrangement (red arrow) (Diff.Quik stain, $\times 270$ ). Inset: Cylindrical cells show long cilia and brush borders similar to the ciliated cells of the respiratory tract (Diff.Quik stain, $\times 430$ ). 
epithelium with cardial glands but most of the cystic wall was lined by a pseudostratified columnar ciliated epithelium (Figure 3). These features were consistent with a diagnosis of foregut duplication cyst of the stomach.

\section{Discussion}

GDCs with a pseudostratified columnar ciliated epithelium (also named foregut duplication cysts of the stomach) are supposed to originate from a respiratory diverticulum, arising from the ventral foregut [7]. This type of gastric duplication is very rare. Including the present report, there have so far been only 21 reported cases. Evaluating patient data, summarized in Table 1, gastric FDCs seem to be a late-onset disease with no differences in relation to gender. In most cases these lesions are located in the upper part of the stomach: at the level of the cardia, near the gastroesophageal junction, or in the anterior or posterior wall of the fundus. Very often, as in our patient, they are asymptomatic and incidentally found. Symptoms, when present, are not specific, including mainly abdominal or epigastric pain. Consistency of FDCs can range from a thin free-flowing fluid to thick proteinaceous material [8].

Despite advances in imaging, cysts that contain solid secretions can often be misclassified as soft tissue masses. A rate of computed tomography misdiagnosis ranging from 43 to $70 \%$ of cases has been reported $[9,10]$. Magnetic resonance imaging does not seem to significantly improve diagnostic accuracy [6]. Therefore, in the majority of the reported cases, a definite diagnosis was made only during surgical resection or by pathological examination on surgical specimens [11-14]. EUS is currently the best available method for the diagnosis

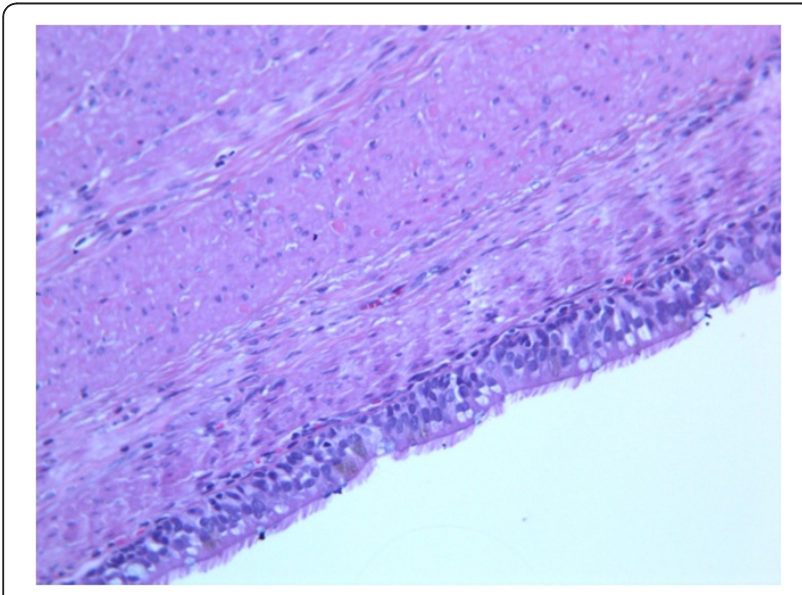

Figure 3 Histology on surgical specimen. Histological sections of the cystic wall showing a cylindrical pseudostratified mucosa on a muscular wall. Epithelial cells show cilia as in the ontogenesis of primitive gut (hematoxylin and eosin, $\times 270$ ). of the subepithelial lesions of the gastrointestinal tract. This technique has also been proved to be superior to computed tomography scan in distinguishing cystic from solid masses [1], but the diagnostic accuracy of EUS is affected by the variation of intracystic contents. The use of contrast-enhanced EUS may also be very useful in the differential diagnosis of digestive diseases $[15,16]$. However, we did not find in the literature any paper discussing the role of contrast-enhanced EUS in the diagnostic evaluation of GDCs.

On the basis of EUS morphologic findings alone, a GDC may be misdiagnosed as a GIST, which is the most common gastric subepithelial lesion, as in the case reported by Jiang and colleagues [17]. In the present case, EUS findings also suggested a diagnosis of GIST. Since the surgical treatment of GISTs involving the upper part of the gastric wall may require an extended gastric resection, we performed EUS-guided FNAC in order to confirm the diagnosis. While inserting the needle we realized that the presumed GIST was a cystic lesion, and the cytological sampling led to a diagnosis of GDC with respiratory epithelium. There are only few case reports concerning EUS-guided FNAC of gastrointestinal duplication cysts $[1,10,18-20]$, but since respiratory-type cells or detached ciliary tufts are visualized in cytologic preparations, a definite diagnosis can be easily made [10]. Pitfalls can occur if the cyst is lined by gastric epithelium only, as in the case described by Wang and colleagues [1]. EUS-guided FNAC led to a cytological misdiagnosis of gastric mucinous neoplasm.

Owing to the report of gastric cancer arising in gastric duplication [2,21-23], surgery is nowadays considered the standard treatment for these lesions [24]. The possibility of a malignant transformation is related to the presence of a gastric-type lining epithelium. Ponder and Collins therefore suggested that surgery is not necessary if respiratory epithelium is recognized on EUS-guided FNAC [20]. Nevertheless, it has been shown in the FDCs of the stomach that pseudostratified columnar ciliated epithelium may be associated with gastric epithelium [24], which could be missed by cytological sampling. For this reason, it may be that a complete surgical excision of the cyst should be recommended; also, in selected cases, some authors consider its observation as a reasonable option. A surgical procedure that does not require a gastric resection can be easily undertaken by a laparoscopic approach, as performed in this case.

\section{Conclusion}

In summary, GDCs - particularly those with respiratory epithelium - represent a rare disease, often misdiagnosed as GISTs, which are more common. Nevertheless, these lesions should be considered in the differential diagnosis of subepithelial gastric masses, 
Table 1 Gastric duplication cyst lined by pseudostratified columnar ciliated epithelium

\begin{tabular}{|c|c|c|c|c|}
\hline References & Age (year) & Gender & Complaint & Location \\
\hline Gensler et al., 1966 [8] & 46 & $\mathrm{~F}$ & No & NGEJ, GC \\
\hline Takahara et al., 1996 [9] & 25 & M & No & Fundus, PW \\
\hline Kim et al., 2000 [10] & 35 & M & Epigastric pain & NGEJ, LC \\
\hline Hedayati et al., 2003 [11] & 59 & $\mathrm{~F}$ & No & Fundus, LC \\
\hline Melo et al., 2005 [12] & 39 & $\mathrm{~F}$ & No & Fundus \\
\hline Rubio et al., 2005 [13] & 26 & M & Epigastric pain & NA \\
\hline Song et al., 2005 [14] & 62 & $\mathrm{~F}$ & No & NGEJ, LC \\
\hline Lee et al., 2006 [15] & 38 & $\mathrm{~F}$ & No & Cardia, LC \\
\hline Cunningham et al., 2006 [3] & 63 & $\mathrm{~F}$ & Fever, abdominal pain & Fundus, PW \\
\hline Wakabayashi et al.,2007 [16] & 37 & M & Epigastric pain & NGEJ, LC \\
\hline Hall et al., 2007 [17] & 40 & M & Epigastric discomfort & NGEJ, LC \\
\hline \multirow[t]{2}{*}{ Theodosopoulos et al.,2007 [18] } & 46 & $\mathrm{~F}$ & Vomiting & (1) Fundus PW; \\
\hline & & & & (2) Gastrosplenic lig. \\
\hline Sato et al., 2008 [19] & 60 & $\mathrm{~F}$ & No & Cardia, LC \\
\hline Murakami et al., 2008 [20] & 72 & $\mathrm{~F}$ & No & Middle body, LC \\
\hline Shibahara et al., 2009 [21] & 43 & M & Epigastric pain & Cardia, LC \\
\hline Mardi et al., 2010 [22] & 42 & M & Left lumbar pain & Cardia, LC \\
\hline Jiang et al., 2010 [23] & 25 & $\mathrm{~F}$ & Epigastric pain & Fundus \\
\hline Jiang et al. 2011 [24] & 76 & M & No & NGEJ, LC \\
\hline \multirow[t]{2}{*}{ Khoury et al. 2011 [7] } & 29 & M & Abd pain & Fundus GC \\
\hline & 26 & $\mathrm{~F}$ & Epigastric pain & Middle body LC \\
\hline Present & 56 & M & No & NGEJ, AW \\
\hline
\end{tabular}

M: male; F: female; NGEJ: near gastroesophageal junction; LC: lesser curvature; GC: greater curvature; PW: posterior wall; AW : anterior wall, NA : not available.

especially if located in the upper part of the gastric wall. Using this technique we will not take any chance on treating a FDC of the stomach through unnecessary extended gastric resection.

\section{Consent}

Written informed consent was obtained from the patient for publication of this case report and any accompanying images. A copy of the written consent is available for review by the Editor-in-Chief of this journal.

\section{Abbreviations}

EUS: endoscopic ultrasound; FDC: foregut duplication cyst; FNAC: fine-needle aspiration cytology; GDC: gastric duplication cyst; GIST: gastrointestinal stromal tumor.

\section{Competing interests}

The authors declare that they have no competing interests.

\section{Authors' contributions}

VN and GC contributed equally to this work. VN, AMP and GC contributed to the conception of the article. VN performed the EUS procedures. GC performed the surgical procedure. PZ and MD'A provided cytological and pathological analysis and contributed to the discussion. PS, AP, CDP and SN were responsible for the review of the literature and drafted the article. VN and PS wrote the paper. AMP and GC revised the manuscript and approved the final version. All authors read and approved the final manuscript.

\section{Author details}

'Department of General and Specialistic Surgery, School of Medicine, Second University of Naples, 5 S. Pansini Street, Naples 80100 , Italy. ${ }^{2}$ Department of Pathology, School of Medicine, Federico II University of Naples, Naples 80100, Italy.

Received: 24 May 2012 Accepted: 18 January 2013

Published: 2 February 2013

\section{References}

1. Wang B, Hunter WJ, Bin-Sagheer S, Bewtra C: Rare potential pitfall in endoscopic ultrasound-guided fine needle aspiration biopsy in gastric duplication cyst: a case report. Acta Cytol 2009, 53:219-222.

2. Coit $\mathrm{DG}$, Mies $\mathrm{C}$ : Adenocarcinoma arising within a gastric duplication cyst. J Surg Oncol 1992, 50:274-277.

3. Cunningham SC, Hansel DE, Fishman EK, Cameron JL: Foregut duplication cyst of the stomach. J Gastrointest Surg 2006, 10:620-621.

4. Ribet ME, Copin MC, Gosselin B: Bronchogenic cysts of the mediastinum. J Thorac Cardiovasc Surg 1995, 109:1003-1010.

5. Murayama S, Murakami J, Watanabe H, Sakai S, Hinaga S, Soeda H, Nakata H, Masuda K: Signal intensity characteristics of mediastinal cystic masses onT1-weighted MRI. J Comput Assist Tomogr 1995, 19:188-191.

6. Fazel A, Moezardalan K, Varadarajulu S, Drananov P, Eloubeidi MA: The utility and the safety of EUS-guided FNA in the evaluation of duplication cysts. Gastrointest Endosc 2005, 62:575-580.

7. Khoury T, Rivera L: Foregut duplication cysts: a report of two cases with emphasis on embryogenesis. World J Gastroenterol 2011, 17:130-134.

8. Bondestam S, Salo JA, Salonen OL, Lamminen AE: Imaging of congenital esophageal cysts in adults. Gastrointest Radiol 1990, 15:279-281.

9. Takahara T, Torigoe T, Haga H, Yoshida H, Takeshima S, Sano S, Ishii Y, Furuya T, Nakamura E, Ishikawa M: Gastric duplication cyst: evaluation by 
endoscopic ultrasonography and magnetic resonance imaging. J Gastroenterol 1996, 31:420-424.

10. Eloubeidi MA, Cohn M, Cerfolio DR, Chhleng DC, Jhala N, Jhala D, Eltoum JA: Endoscopic ultrasound-guided fine-needle aspiration in the diagnosis of foregut duplication cysts: the value of demonstrating detached ciliary tufts in cyst fluid cancer. Cancer Cytopathol 2004, 102:253-258.

11. Melo N, Pitman MB, Rattner DW: Bronchogenic cyst of the gastric fundus presenting as a gastrointestinal stromal tumor. J Laparoendosc Adv Surg Tech 2005, 15:163-165.

12. Song SY, Noh JH, Lee SJ, Son HJ: Bronchogenic cyst of the stomach masquerading as benign stromal tumor. Pathol Int 2005, 55:87-91.

13. Lee S, Park D, Park J, Kim H, Park S, Kim S, Oh M: Endoscopic mucosal resection of a gastric bronchogenic cyst that was mimicking a solid tumor. Endoscopy 2006, 38(Suppl. 2):E12-E13.

14. Mardi K, Kaushal V, Gupta S: Foregut duplication cysts of stomach masquerading as leiomyoma. Indian J Pathol Microbiol 2010, 53:160-161.

15. Hirooka Y, Itoh A, Kawashima H, Ohno E, Itoh Y, Nakamura Y, Hiramatsu T, Sugimoto H, Sumi H, Hayashi D, Ohmiya N, Miyahara R, Nakamura M, Funasaka K, Ishigami M, Katano Y, Goto H: Contrast-enhanced endoscopic ultrasonography in digestive diseases. J Gastroenterol 2012.

16. Kitano M, Sakamoto H, Kudo M: Endoscopic ultrasound: contrast enhancement. Gastrointest Endosc Clin N Am 2012, 22:349-358.

17. Jiang W, Zhang B, Fu Y, Wang J, Gao S, Zhang S, Wu Y: Gastric duplication cyst lined by pseudostratified columnar ciliated epithelium: a case report and literature review. J Zhejiang Univ-Sci B (Biomed Biotechnol) 2011, 12:28-31.

18. Hall DA, Pu RT, Pang Y: Diagnosis of foregut and tailgut cysts by endosonographically guided fine-needle aspiration. Diagn Cytopathol 2007, 35:43-46.

19. Sato M, Irisawa A, Bhutani MS, Schnadig V, Takagi T, Shibukawa G, Wakatsuki T, Imamura H, Takahashi Y, Sato A, Hikichi T, Obara K, Hashimoto Y, Watanabe K, Ohira H: Gastric bronchogenic cyst diagnosed by endosonographically guided fine needle aspiration biopsy. J Clin Ultrasound 2008, 36:237-239.

20. Ponder TB, Collins BT: Fine needle aspiration biopsy of gastric duplication cyst with endoscopic ultrasound guidance. Acta Cytol 2003, 47:571-574.

21. Shibahara H, Arai T, Yokoi S, Hayakawa S: Bronchogenic cyst of the stomach involved with gastric adenocarcinoma. Clin J Gastroenterol 2009, 2:80-84.

22. Iwanaga T, Koyama H, Takahashi Y, Taniguchi H, Wada A: Diffuse submucosal cysts and carcinoma of the stomach. Cancer 1975, 36:606-614

23. Kuraoka K, Nakayama H, Kagawa T, Ichikawa T, Yasui W: Adenocarcinoma arising from a gastric duplication cyst with invasion to the stomach: a case report with literature review. J Clin Pathol 2004, 57:428-431.

24. Murakami S, Isozaki H, Shou T, Sakai K, Toyota H: Foregut duplication cyst of the stomach with pseudostratified columnar ciliated epithelium. Pathol Int 2008, 58:187-190.

doi:10.1186/1477-7819-11-33

Cite this article as: Napolitano et al: Foregut duplication of the stomach diagnosed by endoscopic ultrasound guided fine-needle aspiration cytology: case report and literature review. World Journal of Surgical Oncology 2013 11:33.

\section{Submit your next manuscript to BioMed Central and take full advantage of:}

- Convenient online submission

- Thorough peer review

- No space constraints or color figure charges

- Immediate publication on acceptance

- Inclusion in PubMed, CAS, Scopus and Google Scholar

- Research which is freely available for redistribution 